\title{
Interactive Hypermedia Programs and its Impact on the Achievement of University Students Academically Defaulting in Computer Sciences
}

\author{
Mohamed Desoky Rabeh \\ Department of Computer Science, Faculty of Community College, Northern Border University, Saudi Arabia \\ Department of Computer Teacher Preparation, Faculty of Specific Education, \\ Mansoura University, Egypt
}

\begin{abstract}
Traditional teaching practices through lecture series in a classroom have shown to have less universal efficacy in imparting knowledge to every student. Some students encounter problems in this traditional setting, especially in subjects that require applied instruction rather than verbal teaching. University students who have problems in understanding computer science have been hypothesized in this study to achieve better results on the application of interactive hypermedia programs in their curricula. The study has, thus, conducted a teaching survey through pretest-posttest control group design where computer science students of the Community College of Northern Border University were selected through nonprobability sampling methodology and were made to undergo traditional teaching followed by interactive hypermedia sessions on the same subject. The evaluations of the change in performance provided results that showed that there existed a statistically significant difference in the mean scores of students after attending the interactive hypermedia program, providing evidence that hypermedia induced educational sessions were better to induce performance of students than those sessions that did not have any hypermedia exposure. However, the study also provided an understanding of limitations such as generalized quantitative experiments on computer science students of the Northern Border University, but the researcher believes that more widespread experimentation of the same kind can help establish the unbiased performance supremacy of hypermedia instruction in improving the academic performance of university students in different subjects.
\end{abstract}

Keywords-Interactive hypermedia program; traditional teaching; university students; computer sciences; achievement; impact

\section{INTRODUCTION}

Though technology is rapidly transforming how individuals live and work, the majority of the students are seen to have very less exposure to computers, as well as the subject of computer science [1]. The school administrators and principals of the schools are of the view that other subjects, such as science and mathematics are of more importance than computer science. It has also been noted that even though the aforementioned subjects are compulsory in higher education in many regions of the world, computer science is provided to the curriculum as an optional subject, and the students opting for these subjects are very less [1], [2]. The less exposure to the subject increases the chances of defaulting in the same in higher education, such as when the student reaches college and university level. Many low-income countries also prioritize their curricula in accordance to the budgets, where many students are not made accustomed to a computer due to low budgets of procuring enough that all students can become familiar with the processes and technology [3]. Also, the existing curricula for computer science lack core elements such as programming and coding, instead of teaching how to use applications such as Office, without any chance of providing any advanced courses in computer science [4]. These challenges show the need of creating a different curriculum for computer science for students at the school, college and university level so that there is increased familiarity with the computer science as a subject and also in programming languages and coding as advanced courses for decreasing the level of defaulters in the academics.

There are various processes that can be implemented to change the present situation of computer science, such as allocating budget for specific subject groups, conducting workshops and seminars on the importance of computer science in the professional world due to increased use of technology in day-to-day life, but the most impactful change that can bring about a considerable change is the implementation of a modified and better curricula for computer sciences in various levels of academic learning [5]. Teaching strategies that can help the students to increase their interest and also their skills are through increased interaction, but the most important strategy that can work is an interactive program that uses computer to show graphics, media such as images and videos to aid towards the progression of understanding among students that have had problems with computer science and are academically defaulting on the subject [4].

Student learning is a process that involves many factors apart from the cognitive skills of the student in question, but also on the process or mode of teaching, mood and motivation, teacher's skills in teaching and the process of uptake of the lesson by the student [6]. The process of student-teacher interaction has been a tradition for many decades, but with the advent of technology in every sphere of an individual's life, there has been a rise of new processes that can help students and teachers in conducting the curricula of a particular course. The advancements seen in the media industry have seen a rise in the hypermedia processes, where the programs that use images and videos to put, a point across, has become a new 
interface for teaching and has also led to an opening for teachers who want to increase the level of performance in their specific subjects [7]. Hypermedia programs are learning process programs that use web-based application and adaptive learning environments to provide a personalized learning experience for the students and help increase the level of teaching methods [8]. It has also been noted that the programs that come under the hypermedia can be tailored as per the needs of the students of that particular subject, and the teachers have the support of the interactive multimedia through coursework design so that students' performance increases in the subject of computer science. The hypermedia programs are developed in a way that they stimulate different aspects of a student's mind as they have different types of content as per the age range of the students [9]. The coursework which is supported by hypermedia programs is able to improve the performance of students on a specific topic. The most important need for this program, however, is that the teachers need to be updated with the learning, academic content so that the theoretical content of the program is aligned with the programs, and the teacher is able to use the support of multimedia in their individual teaching and support learning of their respective students. It has also been noted that there are certain types of students with different learning styles that are able to perform better in the hypermedia course, ones that were not able to grasp concepts in a traditional learning environment [6]. The academic ability is generally observed to be the deciding factor for success in academic pursuit, by recent researchers also suggests that learning on an individual level through different strategies might help in increasing the level of learning outcomes. Being able to match the individual preferences in a traditional lecture setting is difficult for the teachers, however, the programs offered by hypermedia and its assisted teaching processes are able to enhance the quality of interaction between a student and a teacher, leading the vulnerable and defaulting category of students to thrive away from a traditional setting [10]. Here, it is also important for teachers to be innovative and creative to understand which alternative method will help a defaulting student create more interest in learning computer science. The use of various ICT tools and courseware in multimedia can help in the learning process that aims to stimulate the interest of these students in computer science [11]. Thus, hypermedia can become a good tool in the teaching arena that involves creating interest and participation of students in stimulating faster uptake of lessons and more precise learning. By promoting interest and creating a sense of academic adventure through graphics, animation, audio, and text, the program can act as a catalyst in delivering better performance outputs and effectively help the students become performers in the said subject of computer science [12].

\section{NEED FOR THE STUDY}

Through the literature review, it can be assessed that there has been little to no research on the effectiveness of hypermedia programs in decreasing the chances of students' defaulting in computer science at the university level, specifically by creating processes that can lead them to achieve high in the subject instead. Thus, this research has been conducted to understand the impact of hypermedia in increasing chances of academic achievement in students that otherwise default in computer science, and to assess the significant difference that the hypermedia programs brings into the performance of these different groups of students, through a pre and post-test analysis. Additionally, the study also seeks to analyze whether the hypermedia programs are significant enough in improving academic score to be included in the curriculum of the Northern Border University.

\section{AIMS OF THE STUDY}

The aims of the study are to analyze the effect of a proposed hypermedia program based on Interactive processes have on the achievement of university students, who are otherwise academically defaulting in computer sciences and provide a significant assessment of the choice to include it in the curriculum of the university. The research questions that needed to be answered through this were:

a) What is the impact of a proposed program based on interactive multimedia to teach the computer skills on the achievement of students who failed to study at the Faculty of Community at Northern Border University?

b) Are there statistically significant differences between the average scores of the students (the research sample) in the pre-application and the post-application test in favor of the post-application, after exposure to the use of the interactive hypermedia program in the computer, and the average grades through teaching in the usual way?

c) Is the program optimal for application of the same for every student of the course, regardless of their learning abilities?

\section{METHODOLOGY}

For assessing the significant change of students defaulting in computer science program in Community College of Northern Border University, the researchers employed a pretest-posttest control group design. The process of the test included two stages- first; the students underwent performance tests based on their knowledge on computers gained through traditional teaching methods, followed by a period of exposure of hypermedia programs for these students. To achieve the purpose of implementing hypermedia program, the largest interactive program devised by [13]. The program was based on 3 nodes, namely, movie, visualization and ready or commercial nodes. A system used to comprise of hypermedia capabilities such as photo-realistic images, sound generation, real-time animation, with additional peripherals including CDROM, a fixed-disk drive, and a mass storage of at least 500Mbytes. Students were integrated through simulation, wherein each of the questions resembled as below in Fig. 1.

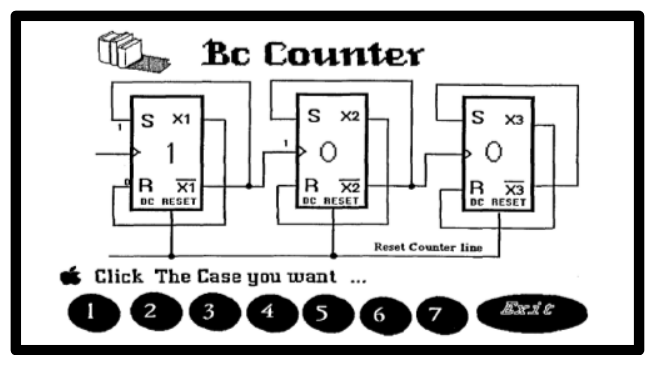

Fig. 1. Simulation of the binary counter (Source: [13]). 
Upon completion of the hypermedia program, Stage 2 commences where students' knowledge of computers was evaluated through post-test. A particular set of students (N-30) enrolled in the Northern Border University was evaluated for both the tests to measure the degree of change in their acquired knowledge. The students have been chosen through purposive non-probability sampling methodology, as the objective of the study is only to measure the difference in performance of 30 students reading in a class before and after implementation of the hypermedia program. An experimental survey strategy was applied to data collection where an achievement test designed by the researcher was used to measure the performance. Upon obtaining prior permission from the University authority and in-charge of a particular class, and fixing a date to conduct the survey, data collection was carried by the distribution of achievement test questionnaires. The aim of the study was explained to the students followed by asking them to answer options, which they perceive as proximally correct. Upon collecting the data of pre-test, the hypermedia program for learning computer science was introduced to the students for a month. Observations on their degree of involvement and learning were noted, followed by the post-test applying the same achievement test. Answers in both pre- and post-test were measured on a dichotomous scale of 0 and 1 , where 0 signified incorrect and 1 signified correct answer. Analysis of the scores collected has been conducted using paired samples T-test and ANOVA. While T-test measured the mean difference of preand post-test, ANOVA enabled to measure the mean difference in scores of between and within the group for individual tests.

\section{RESULTS}

As the study included only quantitative analysis (through an experimental survey), the researcher used only inferential statistics to deduce the results. In inferential statistical technique paired sample t-test was conducted on the data in both terms individually. The paired-samples t-test is considered to be applied to compare two means for those situations where every participant is involved in both samples [14].

Here, the aim of the study is to study the effect of a proposed program based on Interactive hypermedia on the achievement of university students academically defaulting in computer sciences. The analysis is based on the repeated measures on the same respondents before and after implementing the interactive hypermedia computer program. Therefore, the level of significant differences in the performance before and after implementing the program has been checked using paired sample t-test.

In order to move with the analysis, the assumption of normality has been performed. Shapiro-Wilk normality test has been performed to check the normality due to the small sample size.

In Table I, it can be seen that the average sample score data of 30 students are normally distributed as the significance value is higher than 0.05 . Shapiro-Wilk value of the data collected by variable pre-computer training average performance of the students was $0.75>0.05$, and for the variable post-computer training average performance of the students, it was observed to be $0.057>0.057$.
TABLE I. Normality TeST FOR PRE AND POST-TESTS CONDUCted TO MEASuRe Students’ Performance

\begin{tabular}{|l|l|l|l|l|l|l|}
\hline \multicolumn{1}{|c|}{ Tests of Normality } & \multicolumn{1}{|c|}{ Kolmogorov-Smirnov } & \multicolumn{2}{|l|}{ Shapiro-Wilk } \\
\cline { 2 - 7 } & Statistic & Df & Sig. & Statistic & df & Sig. \\
\hline $\begin{array}{l}\text { Pre- } \\
\text { computer } \\
\text { training } \\
\text { average } \\
\text { performance } \\
\text { of the } \\
\text { students }\end{array}$ & .134 & 30 & .175 & .937 & 30 & .075 \\
\hline $\begin{array}{l}\text { Post- } \\
\text { computer } \\
\text { training } \\
\text { average } \\
\text { performance } \\
\text { of the } \\
\text { students }\end{array}$ & .168 & 30 & .030 & .932 & 30 & .057 \\
\hline
\end{tabular}

After proving that the data is normally distributed the next step is to look for the statistical difference in the performance of the University students before and after implementing the interactive hypermedia computer program.

TABLE II. DESCRIPTIVE FOR PRE AND POST-TEST CONDUCTED ON MEAN SCORES OF STUDENTS

\begin{tabular}{|c|l|l|l|l|l|}
\hline \multicolumn{2}{|c|}{ Paired Samples Statistics } & Mean & N & $\begin{array}{l}\text { Std. } \\
\text { Deviation }\end{array}$ & $\begin{array}{l}\text { Std. } \\
\text { Error } \\
\text { Mean }\end{array}$ \\
\hline \multirow{2}{*}{$\begin{array}{l}\text { Pair } \\
1\end{array}$} & $\begin{array}{l}\text { Pre-computer } \\
\text { training } \\
\text { average } \\
\text { performance } \\
\text { of the } \\
\text { students }\end{array}$ & .26909 & 30 & .085200 & .015555 \\
\cline { 2 - 6 } & $\begin{array}{l}\text { Post- } \\
\text { computer } \\
\text { training } \\
\text { average } \\
\text { performance } \\
\text { of the } \\
\text { students }\end{array}$ & .70485 & 30 & .130561 & .023837 \\
\hline
\end{tabular}

Looking at the above Table II, a notable difference can be seen between the mean and standard deviation for both variables- pre-computer training average performance of the students and post-computer training average performance of the students. The average of average scores of all the students before implementing the hypermedia, interactive program is observed only to be 0.269 ; whereas the average of average scores of students after implementation of hypermedia program is 0.70485 .

Table III shows that the there is no significant association between the average performance of the students before and after training as the significant value is much higher than the standard acceptable level of significant value 0.05 . However, no correlation between both the tests leaves any effect on the significance of t-test. 
TABLE III. CORRELATION BETWEEN THE PRE AND POST-TEST CONDUCTED ON MEAN SCORES OF STUDENTS

\begin{tabular}{|l|l|l|l|l|}
\hline \multicolumn{2}{|c|}{ Paired Samples Correlations } & N & Correlation & Sig. \\
\hline Pair 1 & $\begin{array}{l}\text { Pre-computer training average performance of the students \& Post- } \\
\text { computer training average performance of the students }\end{array}$ & 30 & -.067 & .725 \\
\hline
\end{tabular}

TABLE IV. PAIRED SAMPLE T-TEST FOR MEASURING THE SIGNIFICANCE DIFFERENCE BEFORE AND AFTER IMPLEMENTING THE HYPERMEDIA PROGRAM FOR COMPUTER SCIENCE STUDENTS

\begin{tabular}{|c|c|c|c|c|c|c|c|c|c|}
\hline \multicolumn{10}{|c|}{ Paired Samples Test } \\
\hline & & \multicolumn{5}{|c|}{ Paired Differences } & \multirow{3}{*}{$\mathrm{t}$} & \multirow{3}{*}{$\mathrm{df}$} & \multirow{3}{*}{$\begin{array}{l}\text { Sig. }(2 \\
\text { tailed })\end{array}$} \\
\hline & & \multirow[t]{2}{*}{ Mean } & \multirow{2}{*}{$\begin{array}{l}\text { Std. } \\
\text { Deviation }\end{array}$} & \multirow{2}{*}{$\begin{array}{l}\text { Std. } \\
\text { Error } \\
\text { Mean }\end{array}$} & \multicolumn{2}{|c|}{$\begin{array}{l}95 \% \text { Confidence Interval } \\
\text { of the Difference }\end{array}$} & & & \\
\hline & & & & & Lower & Upper & & & \\
\hline Pair 1 & $\begin{array}{l}\text { Pre- minus Post-computer } \\
\text { training average } \\
\text { performance of the } \\
\text { students }\end{array}$ & -.435758 & .160612 & .029324 & -.495731 & -.375784 & -14.860 & 29 & .000 \\
\hline
\end{tabular}

The above Table IV shows that the average scores obtained by the students in the test conducted after implementing the hypermedia interactive computer program in the University are.43 units higher than before after implementing the hypermedia, interactive computer program. Here, the significance value is less than $<0.05$ which shows that there is a significant difference in the performance of the students before and after implementing the computer program for University students. The higher mean value of average scores obtained post implementation of the computer program also supports the same.

Based on the t-test results it can be seen that the implementation of hypermedia computer program in University affects the difference on the performance as the mean score of the student increase post-program implementation.

\section{EFFECT SIZE OF STUDY PROGRAM}

The value of Cohen's $d$ and the effect-size correlation, $r_{Y \lambda}$ was determined by calculating the mean difference between Result of the achievement test, before and after implementing the hypermedia program for computer science students and then dividing the result using the means and the pooled standard deviation.

Cohen's $d=M_{1}-M_{2} / \square_{\text {pooled }}$

where $\square_{\text {pooled }}=\sqrt{ }\left[\left(\square_{1}{ }^{2}+\square_{2}{ }^{2}\right) / 2\right]$

$r_{Y \lambda}=d / \sqrt{ }\left(d^{2}+4\right)$

Cohen's d $=-3.9528$

Effect-size $=0.8922$

The calculation of the Cohen's d value and the correlation size effect showed that there was a large effect size equal to 0.8922 after attending the interactive multimedia program. Thus, the proposed program based on interactive media to achieve academically backward university students in computer science affect the performance of students.
The results from this study suggest that the effects of using hypermedia in instruction are positive over the non hypermedia instruction as a whole, however, the effects may be varied depending on what type of instruction that hypermedia compares to.

TABLE V. ANOVA Table For Measuring the Significance of Mean DIFFERENCE BETWEEN THE SCORES OF ALL 30 STUDENTS BEFORE IMPLEMENTING THE HYPERMEDIA PROGRAM

\begin{tabular}{|l|c|c|c|c|c|}
\hline \multicolumn{7}{|c|}{ ANOVA } \\
\hline \multicolumn{7}{|c|}{ Effect of interactive hypermedia program on computer science } \\
students \\
\hline & $\begin{array}{c}\text { Sum of } \\
\text { Squares }\end{array}$ & df & $\begin{array}{c}\text { Mean } \\
\text { Square }\end{array}$ & F & Sig. \\
\hline $\begin{array}{l}\text { Between } \\
\text { Groups }\end{array}$ & 1.367 & 14 & .098 & 1.098 & .428 \\
\hline $\begin{array}{l}\text { Within } \\
\text { Groups }\end{array}$ & 1.333 & 15 & .089 & & \\
\hline Total & 2.700 & 29 & & & \\
\hline
\end{tabular}

While looking at the above ANOVA Table V, it has been observed that before imposing the interactive hypermedia program for enhancing the computer skills of students there was not a statistically significant difference in the average scores of all students. The same has been deduced based on the significant level less than the standard acceptable level of significance p-value $>.05$.

In Table VI, it can be seen that there is a statistically significant difference between the mean score of students after proposing an interactive hypermedia program for increasing computer skills.

TABLE VI. ANOVA Table For Measuring the Significance of Mean DIFFERENCE BETWEEN THE SCORES OF ALL 30 STUDENTS AFTER IMPLEMENTING THE HYPERMEDIA PROGRAM

\begin{tabular}{|l|l|l|l|l|l|}
\hline \multicolumn{7}{|l|}{ ANOVA } \\
\hline \multicolumn{7}{|l|}{ Effect of interactive hypermedia program on computer science students } \\
\hline & $\begin{array}{l}\text { Sum of } \\
\text { Squares }\end{array}$ & df & Mean Square & F & Sig. \\
\hline $\begin{array}{l}\text { Between } \\
\text { Groups }\end{array}$ & 2.200 & 17 & .129 & 3.106 & .026 \\
\hline Within & .500 & 12 & .042 & & \\
\hline
\end{tabular}




\begin{tabular}{|l|l|l|l|l|l|}
\hline Groups & & & & & \\
\hline Total & 2.700 & 29 & & & \\
\hline
\end{tabular}

\section{DISCUSSION}

In this section of the study, the discussion of the findings has been done using the research question developed in the study.

1) What is the impact of a proposed program based on interactive multimedia to teach the computer skills on the achievement of students who failed to study at the Faculty of Community at Northern Border University?

Performing the analysis, it has been observed that the proposed program based on the interactive hypermedia program to teach the computer skills to the students result in improving the performance of the students who failed at the faculty of the community at the Northern Border University. Before imposing the program, the performance of the students was counted to be highly poor, but with the improved quality teaching through implementing the multimedia program at the campus the students' performance improved significantly. Based on which it can be said that the continuous adoption of new innovative technology and innovations for the purpose of improving student's IT and other skills help in developing the skills in students and improving their knowledge base.

A study conducted by Aloraini in [15] on testing the significant difference in the understanding of 20 females before and after using a multimedia computer-based presentation program showed that after implementing the computer-based interactive program there was a statistically significant difference in average scores of female students. On the other hand, the lecture delivered using traditional approach of dialogue and discussion did not show any statistically significant difference in the mean score of the female students. Osman Ilhan \& Oruç in [16] aiming towards examining the effectiveness of the multimedia program on the academic success of 4th-grade students in Kayseri, Turkey also showed the consistency with the results obtained in the current study. This study was performed on 67 students of 4th class who were studying social studies section where I was treated as a control group and section II was referred to the experimental group. Further, it was concluded that multimedia program has a positive effect on student's academic success. Another study carried out by Nusir et al in [10] has also shown consistency with the results of the current study. This study was also performed using two specific groups and the difference in the performance of their scores in mathematics. It was found that the multimedia attracts the students and improve their level of learning math, which helps the students in performing well in their studies.

Thus, the implementation of the multimedia program would not only help the students in sharpening their future but also help the tutors and University management in understanding how they can improve the interest of students towards learning the computer. At the end, it can be said that the rapidly changing technology has a positive significant effect on the education of students. The multimedia program has increased the success of students in a more enjoyable and positive way.
2) Are there statistically significant differences between the average scores of the students (the research sample) in the pre-application and the post-application test in favor of the post-application, after exposure to the use of the interactive hypermedia program in the computer, and the average grades through teaching in the usual way?

While running the t-test on the mean of a student's score obtained before imposing the proposal of interactive hypermedia and the after imposing it has been obtained, there was the statistically significant difference between the average scores obtained. After exposure received by the students due to using the interactive hypermedia program a significant improvement in the score of students was observed. While looking at the value of mean scores in case of the traditional teaching way the mean scores of the students were highly poor. Implementing the hypermedia program can help in raising the performance. Examining the effect of multimedia materialbased learning on two groups who received traditional and multimedia both types of materials (Yamauchi, 2008) in [5] showed that in pretest and posttest there was no statistically significant difference in the average scores of the students. (Shah \& Khan, 2015) in [17] showed that there is a statistically significant difference between the average scores of the students' post providing multimedia-based teaching. On the other hand, there was no statistical difference in the mean scores of the students while providing traditional teaching. The current study has also shown the similarity with the results achieved in this study.

3) Is the program optimal for application of the same for every student of the course, regardless of their learning abilities?

Based on the results obtained from ANOVA, it can be seen that there is a statistically significant difference between the mean score of students after proposing an interactive hypermedia program for increasing computer skills. All the students in a course have a different level of learning abilities. However, combining the average scores of all students together, there is a statistically significant difference in the performance of the students between pre and post implementation of interactive hypermedia program. Therefore, it can be said that proposing the interactive hypermedia program is beneficial for the students, regardless of their abilities.

\section{STUDY IMPLICATIONS}

This entire study has focused on understanding the difference in the student's performance before and after implementing the hypermedia program in the University. The study may further help the students in understanding the effectiveness of the hypermedia digital program on their performance and thereby adapting themselves as per the new coursework for their future growth. The study has also helped in understanding the difference between the teaching way through traditional and advance digital media programs and their performance on the student's performance. Based on the findings obtained in the study the management can improve the performance of the students emphasizing more on hypermedia programs as part of their curriculum and pedagogy over 
traditional approaches, thereby improving the teaching standards of the University in turn.

\section{LiMiTATIONS}

This entire study has focused on understanding the process of hypermedia in increasing chances of academic achievement in students that otherwise default in computer science, and to assess the significant difference that the hypermedia programs brings into the performance of these different groups of students, through a pre and post-test analysis. Though the research has met the objective of the study, the study is entirely based on only quantitative experiments done on the same sample set and its extent is limited to the students of the Northern Border University only. The generalization of the study may also have lesser scope due to the limited research conducted on the computer science students of the Northern Border University. Moreover, the study is quantitative study, if done qualitative study through interviews of teachers at the University the scope would have been clearer.

\section{CONCLUSIONS}

This study suggest that the effects of using hypermedia program in education are positive over the non-hypermedia education where the correlation size effect showed that there was a significant impact size of 0.8922 after students were exposed to the interactive hypermedia program. Though the researcher has tried to uncover the difference between the performances of computer science students before and after implementing the hypermedia program for enhancing computer skills, still there remain the facts uncovered which can be covered up in future studies. The future may explore the effectiveness of digital media program on the student's performance riding in the different domain also. In addition, the qualitative study may be performed to know the perception of teachers on students' performance through implementing the hypermedia digital program for students' learning skills. In addition, there have been only two pre and posted; there must be repeated tests so that the reliability of the implementation of digital media program can be ensured. Similar studies can be performed on a large sample size including the computer science students of another university as well. This will ensure the consistency in findings of this current study.

\section{ACKNOWLEDGMENT}

The author wish to acknowledge the approval and the support of this research study by the grant $\mathrm{N}^{\circ}$ (6934-COM2017-1-7-F) from the Deanship of the Scientific Research in Northern Border University (N.B.U.), Arar, KSA and all the collaborators in this study.

\section{REFERENCES}

[1] Delen, E., \& Bulut, O. (2011). The relationship between students' exposure to technology and their achievement in science and math. TOJET: The Turkish Online Journal of Educational Technology,10(3), 1 .

[2] Fetler, M. (1985). Sex differences on the California statewide assessment of computer literacy. Sex Roles, 13 (3), 181-191.

[3] Meerbaum-Salant, O., Armoni, M., \& Ben-Ari, M. (Moti). (2013). Learning computer science concepts with Scratch. Computer Science Education, 23(3), 239-264.

[4] Hazzan, O., Lapidot, T., \& Ragonis, N. (2015). Guide to teaching computer science: An activity-based approach. Springer.

[5] Yamauchi, L. G. (2008). Effects of multimedia instructional material on students' learning and their perceptions of the instruction. Iowa State University.

[6] Zarei, A., Yusof, K., \& Daud, M. (2016). A NOVEL APPROACH OF MULTIMEDIA INSTRUCTION APPLICATIONS IN ENGINEERING EDUCATION. Journal of Theoretical and Applied Information Technology, 93(2), 472.

[7] Mora, J. (2012). The Analysis of Interactive Media and Digital CultureHypermedia Literacy in Peru and Bolivia/Medios interactivos y cultura digital: Alfa betización hipermedia en Perú. Comunicar, 20(39), 139.

[8] Sun, P., \& Cheng, H. (2007). The design of instructional multimedia in e-Learning: A Media Richness Theory-based approach. Computers \& Education, 49(3), 662-676.

[9] Pun, M. (2014). The use of multimedia technology in English language teaching: A global perspective. Crossing the Border: International Journal of Interdisciplinary Studies, 1 (1), 29-38.

[10] Nusir, S., Alsmadi, I., Al-Kabi, M., \& Sharadgah, F. (2013). Studying the Impact of Using Multimedia Interactive Programs on Children's Ability to Learn Basic Math Skills. E-Learning and Digital Media, 10(3), 305-319. https://doi.org/10.2304/elea.2013.10.3.305

[11] Alhajri, R., \& Alhunaiyyan, A. A. (2017). Understanding the Impact of Individual Differences in Learner Performance Using Hypermedia Systems. International Journal of Web-Based Learning and Teaching Technologies (IJWLTT), 12(1), 1-18.

[12] Chandler, P. (2009). Dynamic visualisations and hypermedia: Beyond the "Wow" factor. Computers in Human Behavior, 25(2), 389-392.

[13] Nasri, A. H. (2006). Developing a Hypermedia System for Computer Systems Education. Computer Science Education, 6(1), 33-47. Retrieved from http://dx.doi.org/10.1080/0899340950060103

[14] Prophet. (1997). Do your data violate paired t test assumptions?

[15] Aloraini, S. (2012). The impact of using multimedia on students' academic achievement in the College of Education at King Saud University. Journal of King Saud University - Languages and Translation, 24 (2), 75-82. https://doi.org/10.1016/J.JKSULT.2012.05.002

[16] Osman Ilhan, G., \& Oruç, Ş. (2016). Effect of the use of multimedia on students' performance: A case study of social studies class, 11 (8), 877882. https://doi.org/10.5897/ERR2016.2741

[17] Shah, I., \& Khan, M. (2015). Impact of Multimedia-aided Teaching on Students' Academic Achievement and Attitude at Elementary Level. US-China Education Review A, 5(5), 349-360. https://doi.org/10.17265/2161-623X/2015.05.006 